\title{
EFFECT OF THE ADDITION OF DEXAMETHASONE ON THE EFFECTIVENESS AND DURATION OF THE SCIATIC-POPLITEAL BLOCK WITH ROPIVACAINE FOR HALLUX SURGERY
}

\author{
Gómez Martín A. ${ }^{1}$, Gutiérrez González C. ${ }^{2}$, García González N. ${ }^{2}$, Noguerol del Cid C. ${ }^{2}$, \\ Álvarez Arias C. ${ }^{2}$, Posada Mesa L.F.1 \\ ${ }^{1}$ Hospital San Agustín, Aviles, Spain, ${ }^{2}$ Hospital Universitario Central de Asturias, Oviedo, Spain
}

\section{BACKGROUND}

Sciatic-Popliteal Blockade (SPB) provides a good anesthetic level during Hallux surgery. The addition of adjuvant drugs to local anesthetics (LA) improves the quality of nerve plexus blockade, including dexamethasone (DXM) because of its antiinflammatory and decreasing vascular permeability effect.

\section{GOAL OF STUDY}

The aim of our study is to assess the effect of DXM on the duration of postoperative analgesia in Hallux surgery, comparing local administration versus intravenous.

\section{MATERIALS AND METHODS}

Prospective, randomized study in patients scheduled for Hallux Valgus Surgery under sedation (Midazolam 2mg) and SPB as follows:
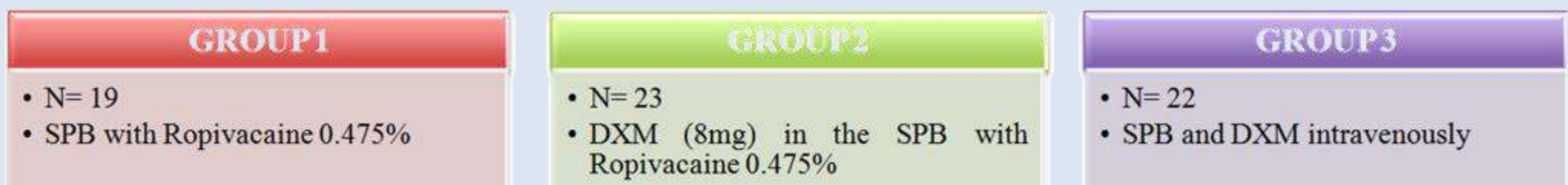

- Demographic and intraoperative variables: Age, ASA (American Society of Anesthesiologists classification), weight, duration of surgery and consumption of analgesics and opioids.

- Postoperative variables: VAS (Visual Analogic Scale), duration of sensory and motor blockade, rescue analgesia, side effects and readmissions.

Statistical analysis: ANOVA (Analysis of Variance) with SPSS v18.0.

\section{RESULTS}

$\checkmark$ No statistically significant differences were found for demographic and intraoperative variables.

$\checkmark$ There was a longer duration of the sensory blockade in groups 2 and 3 compared to Group 1, although it was not statistically significant.

$\checkmark$ There were also no statistically significant differences regarding VAS and duration of motor block between the 3 groups.

$\checkmark$ We found significantly differences in number of readmissions.

$\checkmark$ Only one of the patients in Group 1 required general anesthesia and no side effects were reported due to the drug.

\section{DURATION OF SENSORY BLOCKADE (Hrs)}

$\square$ SCP with Ropivacaine $0,475 \%$

$\square \mathrm{DXM}(8 \mathrm{mg})$ in the SPB with Ropivacaine $0,475 \%$ $\square$ SPB and DXM intravenously

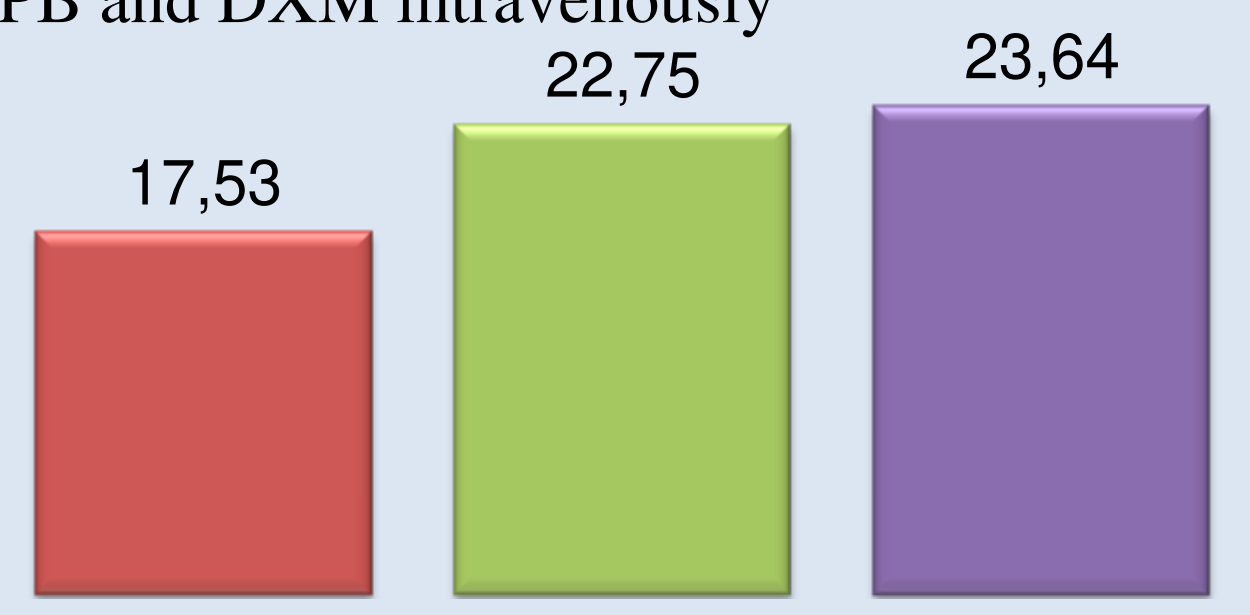

